\title{
MCIT \\ information technol \& \\ Construction of partially linear model of distribution coronevirus in ukraine and the world
}

https://doi.org/10.31713/MCIT.2020.30

\author{
Vasyl Zaiats, \\ University of Technology and Science (UTP) \\ Department of Telecommunication and Computer Science, \\ Bydgoszcz, Poland \\ e-mail addresks zvmmvz01@gmail.com
}

\begin{abstract}
The author proposes a piecewise linear model of the spread of coronavirus 2019 based on the analysis of statistical studies obtained by the World Health Organization (WHO), the Ministry of Health (MH) of Ukraine and the Center for Mathematical Modeling of the NAS of Ukraine within seven months from appearance of the virus. Based on this model and forecasting the rations of growth of the epidemiological disease at COVID-2019, made estimates of the time of disappearance of virus outbreak and a continuous decrease in the number of diseases of persons in need of hospitalization.

The obtained results have both theoretical and applied significance, as they allow, at least, to plan and lead an active lifestyle, save material and human resources, effectively and adequately respond to the manifestations of viral diseases until their complete disappearance.
\end{abstract}

Keywords-piecewise-linear model; dynamic processes; input data; virus infection; statistic data; coefficient of growth

\section{I.INTRODUCTION}

In the analysis of dynamic processes of complex nature, it is advisable to use the creation of a discrete or piecewise linear model, the approaches to the construction of which are described in [1-8].

When creating new real devices, studying unexplored physical or natural phenomena or processes, building recognition and identification systems that have the desired characteristics of the input signal or unknown characteristics to be studied, it is advisable to conduct analytical or computer modeling and analysis, creating adequate mathematical models of object being developed or studied. This approach requires much less time and technical resources compared to a physical or field experiment, especially at the preliminary stage of model development or analysis of a complex structured process in the absence of reliable a priori information about the environment and behavior of objects in it.

Recently, discrete models of systems are widely used in nonlinear dynamics [7, 8], for which discreteness is inherent in the nature of the object of study, and is not a consequence of the discretization of a continuous system.
The expediency of using discrete models is explained by the following features:

- simplicity of mathematical description in comparison with continuous models;

- the presence of a significantly wider range of dynamic modes compared to known models;

- infinite dimensionality, which allows to model each new harmonic of the process by introducing it into the vector of state variables, while for continuous systems to solve this problem it is necessary to increase the dimensionality of the system;

- no need to determine the sampling step, assess the local and global errors of numerical methods, areas of stability and synchronization;

- convenience and better adaptability to the computer experiment compared to continuous models.

- the ability to predict the behavior of an object or phenomenon in the future based on incomplete input data

Discrete models are applicable both to the construction of devices with the desired modes and to the recognition and identification of situations in systems with complex dynamics and behavior.

The simplest and closest to discrete models are piecewise linear models, which allows you to analyze them by simple means, preserving the qualitative features of the process and in the first approximation to obtain analytical estimates to predict its behavior.

\section{INPUT DATA}

The aim of this work is to develop the simplest piecewise linear model to describe the process of development of the coronavirus at a given time interval in order to predict to estimate in the first approximation the time when the virus will begin to disappear and the number people that have diseases, starting from a given time interval will not increase. 
he process of spreading the disease at COVID 2019 began in early March 2020 and as of the end of September 2020 is developing rapidly around the world. According to the results of the accumulation of statistics obtained by the World Health Organization [9], the Ministry of Health of Ukraine [10], the Center for Mathematical Modeling of the Academy of Sciences of Ukraine [11], published on the Internet, the average number of human diseases at COVID 2019 during the month almost doubled in the last three months. According to these respected organizations, during the epidemic of COVID 2019 will affect about $50-80 \%$ of the world's population. At the same time $1 \%$ of patients will not be able to overcome the disease. Having such an incomplete set of data, we construct a primitive piecewise linear model to predict the behavior of the disease for the next time period.

\section{APPROACH TO CREATING OF MODEL}

When building the model we will proceed from the available disease statistics for COVID 2019 at the end of each month in 2020 [8], from the end of March to the end of September, as shown in table 1.

TABLE 1. DISEASE STATISTICS FOR COVID-2019 AT THE END OF EACH MONTH OF 2020 IN UKRAINE

\begin{tabular}{|c|c|c|c|c|c|c|}
\hline March & April & May & June & July & August & September \\
\hline 450 & 10490 & 23072 & 45000 & 69000 & 121000 & 208000 \\
\hline
\end{tabular}

The graph of the dependence of the total number of diseases on COVID-2019 at the end of each month of 2020 in Ukraine is shown in fig. 1 As follows from the analysis of the above graph, the total number of diseases $\left(K_{n}\right)$ achieved at the end of the last month continues to grow, compared to the total number of diseases achieved at the end of the previous month $\left(\mathrm{K}_{\mathrm{t}+1}\right)$. Here is the relationship

$$
K_{g}=\frac{K_{n+1}}{K_{\Pi}}
$$

will call by coefficient of growth of morbidity for a given period of time. Obviously, the beginning of the moment of virus extinction will correspond to the critical value $K_{\mathrm{g}}=1$. After reaching this value, the number of diseases will not increase. Over time, the number of illnesses may remain the same if no one is cured during this time or decreases due to recovery or death.

Note that $K_{\mathrm{g}}$ over a period of seven months gradually decreases from 22 to 1.5. This gives cautious optimism to predict that in the future $\mathrm{K}_{\mathrm{g}}$ will decrease in the future, approaching the critical value $K_{\mathrm{g}}=1$.

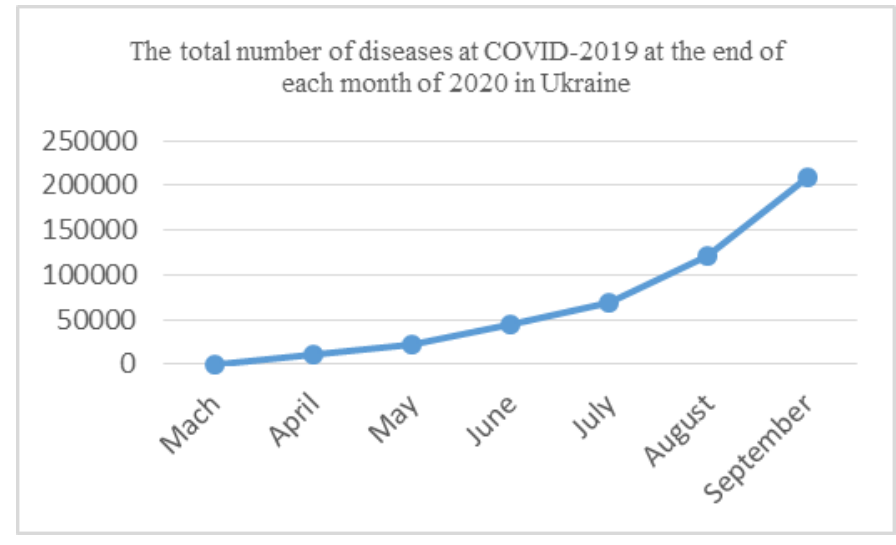

Figure.1. A piecewise linear model of the spread of coronavirus in Ukraine

Even assuming that the incidence rate will remain unchanged

$$
\mathrm{K}_{\mathrm{g}}=1.5
$$

during the period of infection on the KOVID 2019 of the entire population, we will receive an estimate of the period of time during which the incidence rate will not increase. As follows from table. 2 as of March 31, 2021, the growth of the epidemic

TABLE 2. ESTIMATION OF THE TIME OF DISAPPEARANCE OF THE NUMBER OF DISEASES IN UKRAINE

\begin{tabular}{|c|c|c|c|c|c|c|}
\hline $\begin{array}{c}\text { Octo- } \\
\text { ber }\end{array}$ & $\begin{array}{c}\text { Novem- } \\
\text { ber }\end{array}$ & $\begin{array}{c}\text { Decem- } \\
\text { ber }\end{array}$ & $\begin{array}{c}\text { Janu- } \\
\text { ary }\end{array}$ & $\begin{array}{c}\text { Febru- } \\
\text { ary }\end{array}$ & March & April \\
\hline 312000 & 468000 & 702000 & 1053000 & 1580000 & 2370000 & 35537500 \\
\hline
\end{tabular}

in Ukraine will stop, as it will reach $10 \%$ of the infection of the population of Ukraine, which is about 3,600,000 people. In the calculations, such an infection threshold was chosen for the reason that even if the virus infection of half of the population of a given region is eliminated, two thirds of the disease will pass in mild form without hospitalization (self-isolation, strong natural immunity) and half of the remaining more than $20 \%$ will not participate in treatment for a number of reasons, the main of which is their own irresponsibility. In addition, although it is officially considered that in Ukraine lives 40 million people, 5 million of them live or work abroad and, if necessary, will overcome the disease in the territory of stay.

Let's build another model based on the statistical database of diseases at COVID 2019 in the world. Again, we proceed from the available disease statistics for COVID 2019 in the world at the end of each month in 2020 [7-8], beginning from the end of March and to the end of September, as shown in table 3 . 
TABLE 3. DISEASE STATISTICS FOR COVID-2019 AT THE END OF EACH MONTH OF 2020 IN THE WORLD

\begin{tabular}{|c|c|c|c|}
\hline March & April & May & June \\
\hline 724082 & 3000000 & 6000000 & 10000000 \\
\hline July & August & September & \\
\hline 18000000 & 25000200 & 35000100 & \\
\hline
\end{tabular}

TABLE 4. ESTIMATION OF THE TIME OF EXTINCTION GROWS OF THE NUMBER OF DISEASES IN THE WORLD.

\begin{tabular}{|l|c|c|c|c|}
\hline October & November & December & January & February \\
\hline 49000140 & 68600196 & 9040274 & 134456384 & 18823838 \\
\hline March & April & May & June & \\
\hline 263534513 & 368948318 & 516527645 & 723138703 & \\
\hline
\end{tabular}

The graph of the dependence of the total number of diseases on COVID-2019 at the end of each month of 2020 in the world is shown in Fig. 2. As follows from the analysis of the above graph, the total number of $\mathrm{Kg}$ diseases achieved at the end of the last month is almost not increasing compared to the total number of diseases.

Note that the in the world over a period of seven months $\mathrm{Kg}$ gradually decreases from 4.1 to 1.4 . This makes it possible to predict that in the future $K \mathrm{~g}$ will decrease, gradually approaching to one.

Assuming that the incidence rate in the world will remain unchanged in the future

$$
K g=1.4
$$

during the entire period of infection of $10 \%$ of the world's population at KOVID 2019, we will receive an estimate of the period of time during which the incidence rate will not increase. As follows from table 4 as of June 31, 2021, the growth of the epidemic in the world will stop, as it will reach $10 \%$ of the world's population, which will amount to approximately $72,000,000$ people.

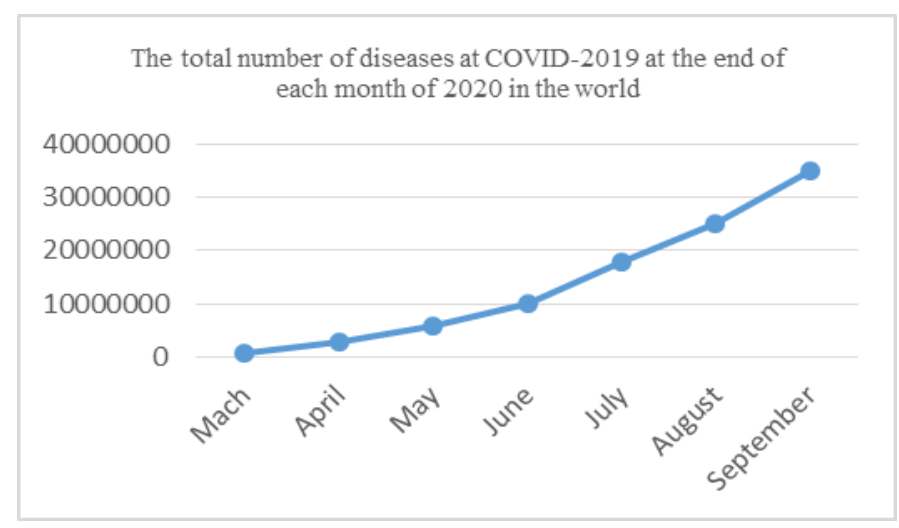

Figure 2. A piecewise linear model of the spread of the coronavirus in the world

This model does not predict how the process of recovery from the virus will take place, because its creation does not take into account a number of factors: treatment and vaccination procedures, the human factor, in particular, compliance with basic rules of personal safety (mask mode, communication distance $1.5 \mathrm{~m}$ ). , constant washing of hands with soap and the use of antiseptics, minimization of contact with the environment while maintaining an active lifestyle), willingness to test for the presence of virus and immunity, environmental impact, and more. All these factors significantly affect the course of the viral disease and if ignored can lead to deplorable consequences. But based on the available means of treatment, it can be argued that after the cessation of the growth of the epidemic of coronavirus within 3-4 weeks, the epidemic will be overcome

\section{CONCLUSION}

The paper proposes a piecewise-linear model of COVID 2019 development, which is based on the analysis of statistical data. The model is open and can be refined in the process of obtaining new information.

Based on this model, preliminary assessments of the spread of the disease both in Ukraine and abroad and predictions for further development of the virus.

It should be noted that today the development of the virus in Ukraine is rapid with a growth coefficient of $\mathrm{Kg}=1.7$, which corresponds to almost doubling the average number of diseases per day at intervals of 1 month. This process has been going on for the last three months. In the world, the epidemic is growing somewhat more slowly with a growth coefficient of $K \mathrm{~g}=1.4$, which has been observed over the past two months

The considered model is a model of the first approximation and needs to be clarified, because it does not take into account the human factor, treatment procedures, vaccination, the impact of human natural immunity on the process.

\section{REFERENCES}

[1] V.M. Zaiats, "Constraction and analises of model descrete oscillation systems", Cybernetics and Systems Analysis, vol. 2, Kiev, NAS of Ukraine, 2000, pp. 161-165.

[2] V.M. Zaiats, "The Models Descrete Oscillation Systems", Computer Tegnology of Print, Lviv,UAP, 2011, pp.37-39.

[3] J. Vlach and K. Singhall, Computer Methods for Circuit Analysis and Design", New York, VNRC, 1980, 560 p.

[4] L. Feldman, A. Petrenko and O. Dmitrieva, Numerical Methods in informatic, Kiev, BHV, 2006, 480 p.

[5] G. Holl and J.M. Watt, Modern Numerical Methods for Ordinary Differential Equations,. Clarendon press, Oxford, 1979, 312 p.

[6] D. Forsait, H.Malkom, K. Mouler, Computer Methods of Mathematics Calculations, Moscow, Peace,1980, 282.p.

[7] V.M. Zaiats, Lviv, Discrete Models of Oscillatory Systems for the Analysis of their Dynamics, UAP, 2011, 284 p.

[8] V.M. Zaiats, Methods, Algorithms and Software for Simulation and Analysis of the Dynamics of Complex Objects and Systems Based on Discrete Models, Lviv, New World, 2009, 400 p.

[9] https://WwW.who.in. .- Internet - resource.

[10] https:// WWW.moz.gov.ua/statistics . - Internet - resource.

[11] https://www.nas.gov.ua/UA/Messages/Pages/View.aspx? $\underline{\text { MessageID }=6598} .-$ Internet - resource.

[12] https://www.pravda.com.ua/cdn/covid-19/cpa/ . Internet resource/ 